\title{
Decrease in the prevalence of smoking among Japanese adolescents and its possible causes: periodic nationwide cross-sectional surveys
}

\author{
Yoneatsu Osaki - Takeo Tanihata $\cdot$ Takashi Ohida $\cdot$ Hideyuki Kanda $\cdot$ Yoshitaka Kaneita \\ Masumi Minowa $\cdot$ Kenji Suzuki $\cdot$ Kiyoshi Wada $\cdot$ Kenji Hayashi
}

Received: 11 October 2007/Accepted: 11 March 2008/Published online: 26 April 2008

(C) The Japanese Society for Hygiene 2008

\begin{abstract}
Objectives To assess trends in smoking prevalence among Japanese adolescents and to analyze possible causal factors for the decrease in smoking prevalence observed in a 2004 survey.

Methods Nationwide cross-sectional surveys were conducted in 1996, 2000 and 2004. Survey schools, both junior and senior high schools, considered to be representative of the whole of Japan were sampled randomly. Enrolled students were asked to complete a self-reporting anonymous questionnaire on smoking behavior. The questionnaires were collected from 115,814 students in 1996, 106,297 in 2000, and 102,451 in 2004. School principals were asked about the policy of their respective school on smoking restrictions.

Results Cigarette smoking prevalence (lifetime, current, and daily smoking) in 2004, based on the completed questionaires, had decreased relative to previous years in both sexes and in all school grades. The most important
\end{abstract}

Y. Osaki $(\bowtie)$

Division of Environmental and Preventive Medicine,

Department of Social Medicine, Faculty of Medicine, Tottori

University, 86 Nishimachi, Yonago, Tottori 683-8503, Japan

e-mail: yoneatsu@grape.med.tottori-u.ac.jp

T. Tanihata

Department of Epidemiology, National Institute of Public

Health, 2-3-6 Minami, Wako, Saitama 351-0197, Japan

T. Ohida $\cdot$ Y. Kaneita

School of Medicine, Department of Public Health,

Nihon University, 30-1 Ohyaguchikami Machi,

Itabashi, Tokyo 173-8610, Japan

H. Kanda

Department of Hygiene and Preventive Medicine,

Fukushima Medical University, 1 Hikarigaoka,

Fukushima, Fukushima 960-1295, Japan trends were: a decrease in smoking prevalence among the fathers and older brothers of the students; an increase in the proportion of students who did not have friends; a decrease in the proportion of current smokers who usually bought cigarettes in stores decreased in 2004, in particular for the oldest boys. An association was found between a lower smoking rate at a school and a smoke-free school policy.

Conclusions Japan has experienced a decrease in the prevalence of smoking among adolescents. A decrease in smoking prevalence among the fathers and older brothers, limitations to minors' access to tobacco, an increase in the proportion of students without friends, and a school policy restricting smoking may have contributed to this decreasing trend.

Keywords Adolescence - Adolescent behavior . Cigarette use $\cdot$ Japan $\cdot$ Smoking behavior

M. Minowa

Department of Human Life and Culture, Seitoku University, 550 Iwase, Matsudo, Chiba 271-8555, Japan

K. Suzuki

Suzuki Mental Clinic, 370 Isshiki,

Hayama, Kanagawa 240-1111, Japan

K. Wada

National Center of Neurology and Psychiatry,

National Institute of Mental Health,

4-1-1 Ogawahigashi Machi,

Kodaira, Tokyo 187-8502, Japan

K. Hayashi

National Institute of Public Health, 2-3-6 Minami,

Wako, Saitama 351-0197, Japan 


\section{Introduction}

Cigarette smoking increases the risk of many diseases. Given the difficulty of escaping nicotine dependence, the prevention of smoking among adolescents has been identified as a major public health measure $[1,2]$. The monitoring of smoking prevalence among adolescents is thus an important means of clarifying the characteristics of this problem, establishing countermeasures, and evaluating public health efforts to reduce smoking prevalence. In the case of Japan, nationwide surveys on cigarette smoking among high school students conducted in 1996 and 2000 [3-5] revealed that many students had started smoking despite the various restrictions to prevent this established by the Act to Prohibit Minors from Smoking, enacted in 1900. To better understand trends in smoking prevalence, we conducted a third nationwide survey in 2004 and found a dramatic decrease in smoking prevalence among Japanese adolescents.

Many articles describe associated factors or predictors of adolescent smoking. Parental or sibling smoking status and peer networks are two well-known factors contributing to smoking among adolescents [6-9]. Therefore, an analysis of the trends in parental or sibling smoking status and peer networks is important for studying factors contributing to the change in smoking prevalence among adolescents. Although it was expected that a school's policy on limiting smoking by teachers would play a positive role in discouraging students from smoking, review papers have summarized that the effect of such school-based smoking control measures is small in Western countries $[10,11]$.

Here, we describe the trends in adolescent smoking prevalence in Japan and analyze the possible factors contributing to a decrease in smoking prevalence among the adolescent population, including parental or sibling smoking status, peer networks, and school regulations on teachers' smoking.

\section{Methods}

\section{Subjects}

The survey was a cross-sectional random sampling survey, which used the single-stage cluster sampling methodology [12]. The cluster unit of the sampling was schools. The survey targeted junior and senior high school students from schools selected throughout Japan using the National School Directory. All students enrolled in the sampled schools were subjects of the study.

The number of schools sampled in the 1996 survey was 122 of 11,274 junior high schools (selection rate: $1.1 \%$ ) and 109 of 5501 senior high schools (2.0\%). The proportion of private schools was $4.9 \%$ for junior high schools and $28.4 \%$ for senior high schools. The proportion of general, vocational and mixed senior high schools was $38.5,23.9$, and $37.5 \%$, respectively. The survey period was December 1996 to the end of January 1997. Respective values for the 2000 and 2004 surveys were 132 of 11,200 junior $(1.2 \%)$ and 102 of 5,315 senior high schools (1.9\%) from December 2000 to the end of January 2001, and 131 of 11,060 junior $(1.2 \%)$ and 109 of 4,627 senior high schools (1.9\%) from December 2004 to the end of January 2005. The proportion of private schools was $7.6 \%$ for junior high schools and $33.3 \%$ for senior high schools in 2000 survey; in the 2004 survey, the proportions were $6.9 \%$ and $26.6 \%$, respectively. The proportion of general, vocational and mixed senior high schools was 48.0, 13.7, and $38.3 \%$, respectively in the 2000 survey and $45.0,22.9$, and $32.1 \%$, respectively, in the 2004 survey.

\section{Procedures}

We requested the cooperation of the principals of these schools and sent these individuals questionnaires for their respective school's student population. The teachers were asked to inform the students of the voluntary nature of their participation and to urge them to answer honestly. Anonymous questionnaires and envelopes were handed to the students for completion during school time. Upon completion, the questionnaires were sealed in the envelopes by the students themselves, collected by their teachers, and returned to our institute unopened. School regulations on smoking by teachers was determined using a school questionnaire completed by the school principal. This survey was approved by the Ethics Committee of the National Institute of Public Health.

\section{Measures}

The questionnaire focused on smoking experience, smoking frequency, age (by school grade) when the respondent first tried smoking, number of cigarettes consumed daily by smokers, sources for cigarettes, and smoking status of the student's family. Experimenting smokers, current smokers, and daily smokers were defined as those who had tried smoking at least once, those who had smoked at least once during the previous 30 days, and those who had smoked every day during the previous 30 days, respectively. Students were defined as having no friend who smoked if they responded that "I have no friend" in the question "Do you have a friend who is a smoker?"-yes/no/I have no friend.

School regulations on smoking by teachers was categorized into four groups, namely (1) completely smokefree throughout the school site, including buildings and 
grounds; (2) smoke-free in all school buildings but not the grounds; (3) appropriate separation of smoking (smoking room); (4) insufficient separation of smoking. Appropriate separation was defined as a completely partitioned smoking room with air exhaust facilities to the exterior.

\section{Response rate}

For the 1996 survey, responses were obtained from 80 junior (response rate 65.6\%) and 73 senior high schools $(67.0 \%)$, with a total of 115,814 responses accounting for $64.1 \%$ of all junior and $62.5 \%$ of all senior students enrolled in the sampled schools. In 2000, the respective values were $99(75.0 \%)$ and 77 schools (75.5\%), with 106,297 responses accounting for 66.1 and $59.3 \%$ of enrolled students, and in 2004, these were $92(70.2 \%)$ and 87 schools $(79.8 \%)$, with 102,451 responses accounting for 60.7 and $67.7 \%$ of students. The defining properties of the responding schools, such as the proportion of private schools, vocational schools, or general schools were chosen to be representative of the study population.

\section{Data analysis}

The percentages and $95 \%$ confidence intervals (95\% CI) in the tables were calculated by a weighting method based on one-stage stratified cluster sampling [12]. Proportions in tables were compared using statistical testing for rate differences. Multiple logistic regression analyses were applied to calculate odds ratios and the population attributable risk percentage for a student's current smoking status with a family member's (father, mother, older brother, and older sister) smoking, and for a student's current smoking status with the absence of a friend. Data were analyzed using the SPSS FOR WINDOWs ver. 13.0 software (SPSS, Chicago, IL).

\section{Results}

Smoking prevalence

Lifetime smoking rate, current smoking rate, and daily smoking rate increased with age. Lifetime smoking rate in 2000 among junior high school boys fell compared with that in 1996, whereas the prevalence of regular smoking (current smoking and daily smoking) did not. In 2004, lifetime, current, and daily smoking rates had decreasedrelative to 1996 and 2000 - in both sexes and in every school grade (Table 1). The magnitude of the decrease was greater in boys than in girls.
Factors accounting for the decrease in smoking prevalence

The data were analyzed to identify the factors for this decreasing trend in smoking prevalence among Japanese adolescents. Reported smoking status of family members showed some decrease in family smoking, especially that by fathers, but smoking by older brothers, older sisters and friends also showed a significant and persistent decrease (Table 2). In contrast, smoking by mothers of junior high school boys and senior high school girls increased. The odds ratios of a student's current smoking status with the smoking by a family member were higher when it was the mother who smoked than when it was the father who smoked. The increasing tendency was observed in the odds ratios when both the father and mother smoked. The odds ratios of father and senior brother among boys were higher than those among girls, whereas the odds ratios of the mother and senior sister among girls were higher than those among boys. The population attributable risks of family's smoking were calculated at $7.7-18.1 \%$ in $1996,8.4-21.7 \%$ in 2000 , and $6.0-25.3 \%$ of the total current smoking rate in 2004; the estimated risk of the father was higher among boys and that of the mother was higher among girls (Table 2).

In our search for factors contributing to the change in smoking prevalence among adolescents, we discovered an increase in the proportion of students who had no friend. In the 1996 and 2000 survey, the proportion of students who reported that they had no friends was quite low; however, this abruptly increased in 2004. Since the smoking prevalence among students who had no friend was lower than that among students who did have a friend, the odds ratios of having no friend were calculated for the values that were smaller than 1.0. The magnitude of the effect was smaller than that of family's smoking but significant for senior high school students (Table 2).

The most common sources of cigarettes for current smokers are cigarette vending machines, stores (convenience store, supermarket, or gas station), and someone else. When the results for 2000 and 2004 were compared, the proportion students getting cigarettes from stores and someone else had decreased in 2004, especially for boys (Table 3).

When the association between the prevalence of smoking among students and the respective school's regulations on smoking by teachers were analyzed, we found that smoking by students in smoke-free schools tended to be lower in both junior and senior high schools. The difference was statistically significant in junior high school girls and in senior high school boys for regular smoking (Table 4). However, smoking prevalence of junior high school students and senior high school girls in the schools 


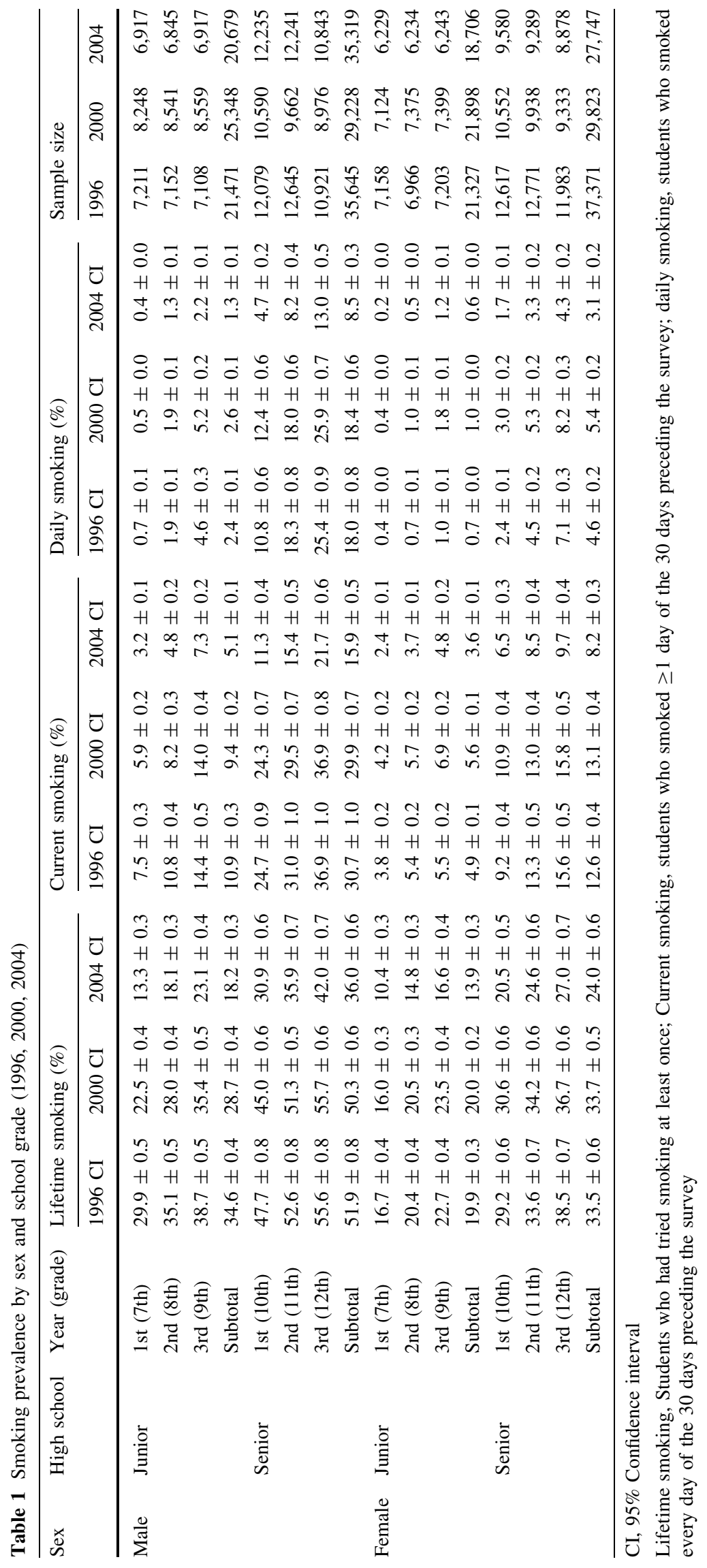




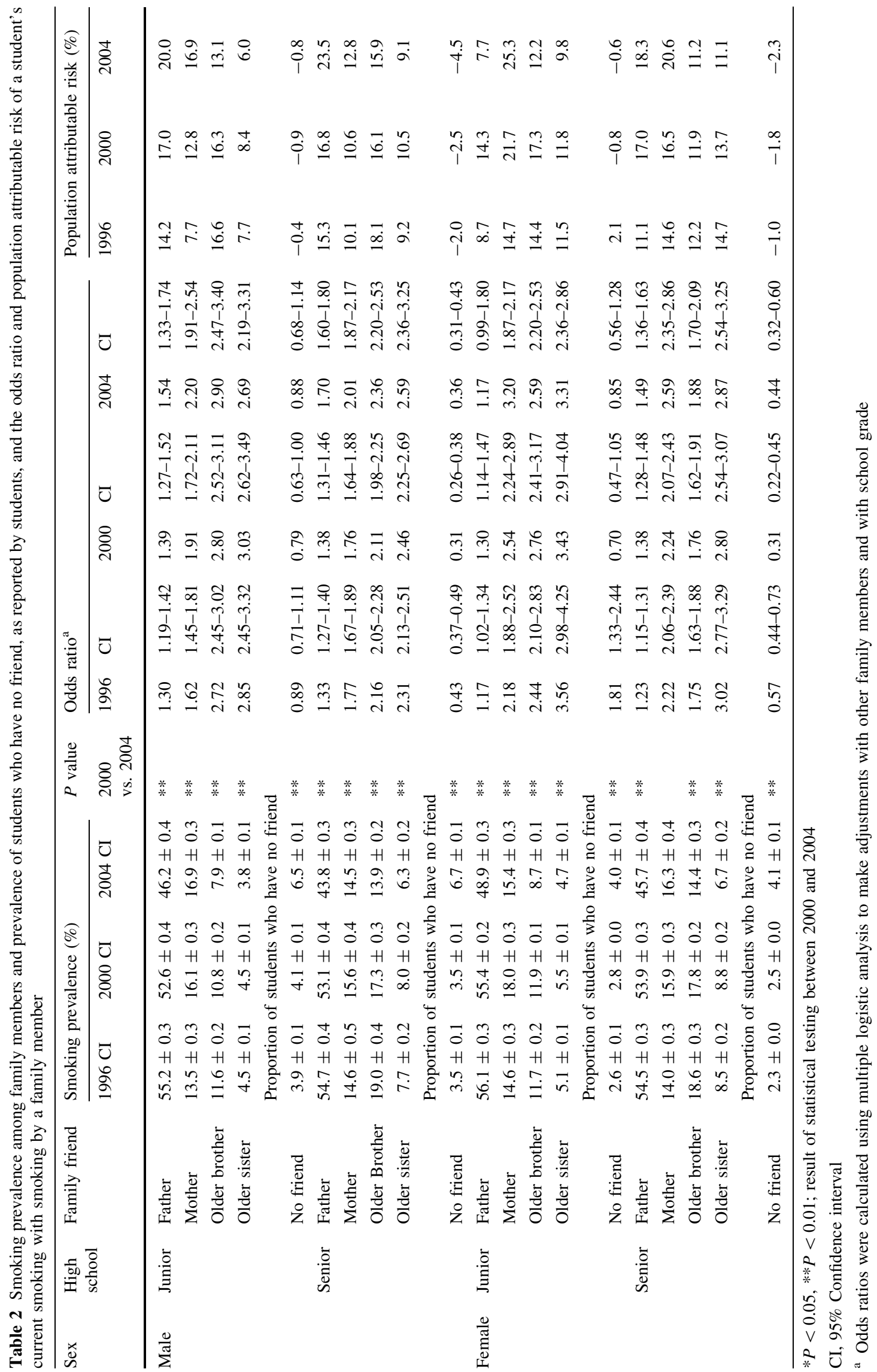


Table 3 Usual sources of cigarettes reported by current smokers

\begin{tabular}{|c|c|c|c|c|c|c|c|c|}
\hline Sex & $\begin{array}{l}\text { High } \\
\text { school }\end{array}$ & Year & $\begin{array}{l}\text { Searching in } \\
\text { house }(\%) \text { CI }\end{array}$ & $\begin{array}{l}\text { Getting from } \\
\text { someone CI }\end{array}$ & $\begin{array}{l}\text { Tobacconist } \\
\text { shop CI }\end{array}$ & Stores CI & $\begin{array}{l}\text { Vending } \\
\text { machine CI }\end{array}$ & $\begin{array}{l}\text { Number of } \\
\text { current smokers }\end{array}$ \\
\hline \multirow[t]{6}{*}{ Male } & \multirow[t]{3}{*}{ Junior } & 1996 & $24.2 \pm 0.3$ & $33.4 \pm 0.2$ & $17.0 \pm 0.2$ & $17.8 \pm 0.3$ & $60.3 \pm 0.4$ & 2,453 \\
\hline & & 2000 & $21.4 \pm 0.2$ & $37.1 \pm 0.2$ & $13.4 \pm 0.2$ & $21.3 \pm 0.2$ & $64.6 \pm 0.2$ & 2,389 \\
\hline & & 2004 & $22.1 \pm 0.5$ & $30.6 \pm 0.8 * *$ & $12.0 \pm 0.2$ & $13.5 \pm 0.2 * *$ & $61.1 \pm 0.4$ & 1,049 \\
\hline & \multirow[t]{3}{*}{ Senior } & 1996 & $15.1 \pm 0.1$ & $30.9 \pm 0.2$ & $27.3 \pm 0.3$ & $42.6 \pm 0.5$ & $84.3 \pm 0.1$ & 11,869 \\
\hline & & 2000 & $14.0 \pm 0.1$ & $33.1 \pm 0.1$ & $26.2 \pm 0.3$ & $49.4 \pm 0.3$ & $85.8 \pm 0.1$ & 8,818 \\
\hline & & 2004 & $13.2 \pm 0.4$ & $29.2 \pm 0.4 * *$ & $20.8 \pm 0.2 * *$ & $41.5 \pm 0.3 * *$ & $82.5 \pm 0.1 * *$ & 5,625 \\
\hline \multirow[t]{6}{*}{ Female } & \multirow[t]{3}{*}{ Junior } & 1996 & $39.4 \pm 0.4$ & $41.6 \pm 0.3$ & $11.7 \pm 0.2$ & $16.1 \pm 0.3$ & $54.0 \pm 0.4$ & 1,048 \\
\hline & & 2000 & $27.8 \pm 0.3$ & $47.5 \pm 0.3$ & $9.0 \pm 0.1$ & $17.9 \pm 0.3$ & $60.7 \pm 0.3$ & 1,206 \\
\hline & & 2004 & $31.5 \pm 1.3$ & $40.8 \pm 1.6 * *$ & $8.9 \pm 0.3$ & $12.7 \pm 0.3 *$ & $59.4 \pm 0.4$ & 677 \\
\hline & \multirow[t]{3}{*}{ Senior } & 1996 & $18.5 \pm 0.2$ & $35.1 \pm 0.2$ & $13.2 \pm 0.3$ & $28.4 \pm 0.5$ & $76.6 \pm 0.2$ & 4,696 \\
\hline & & 2000 & $15.4 \pm 0.1$ & $35.8 \pm 0.2$ & $10.2 \pm 0.1$ & $36.2 \pm 0.3$ & $80.3 \pm 0.2$ & 3,824 \\
\hline & & 2004 & $17.0 \pm 0.6$ & $32.6 \pm 0.8 * *$ & $9.9 \pm 0.2$ & $34.2 \pm 0.3$ & $77.8 \pm 0.2$ & 2,263 \\
\hline
\end{tabular}

CI, 95\% Confidence interval

* $P<0.05$, ** $P<0.01$; result of statistical testing between 2000 and 2004

Percentages add up to more than $100 \%$ as some students mentioned more than one source of cigarettes

Table 4 Association between variables of students' smoking and school smoking regulation

\begin{tabular}{|c|c|c|c|c|c|c|c|c|c|c|}
\hline \multirow[t]{2}{*}{ Sex } & \multirow{2}{*}{$\begin{array}{l}\text { High } \\
\text { school }\end{array}$} & \multirow[t]{2}{*}{ School policy } & \multirow{2}{*}{$\begin{array}{l}\text { Number of } \\
\text { schools }\end{array}$} & \multicolumn{2}{|c|}{ Lifetime smoking } & \multicolumn{2}{|c|}{ Current smoking } & \multicolumn{2}{|c|}{ Daily smoking } & \multirow{2}{*}{$\begin{array}{l}\text { Number of } \\
\text { students }\end{array}$} \\
\hline & & & & OR & CI & OR & CI & OR & $\mathrm{CI}$ & \\
\hline \multirow[t]{8}{*}{ Male } & \multirow[t]{4}{*}{ Junior } & Insufficient separation of smoking & 23 & 1.0 & & 1.0 & & 1.0 & & 5,380 \\
\hline & & Separate smoking areas & 23 & 1.04 & $0.94-1.14$ & 1.05 & $0.88-1.26$ & 1.09 & $0.77-1.55$ & 4,992 \\
\hline & & Smoke-free in school buildings & 19 & 0.99 & 0.89-1.09 & 1.23 & $1.03-1.47$ & 1.44 & $1.02-2.02$ & 4,275 \\
\hline & & Smoke-free throughout school site & 27 & 0.94 & $0.85-1.03$ & 1.01 & $0.85-1.20$ & 0.98 & $0.69-1.38$ & 6,032 \\
\hline & \multirow[t]{4}{*}{ Senior } & Insufficient separation of smoking & 19 & 1.0 & & 1.0 & & 1.0 & & 8,569 \\
\hline & & Separate smoking areas & 28 & 0.91 & $0.86-0.96$ & 0.89 & $0.82-0.96$ & 0.88 & $0.80-0.97$ & 10,649 \\
\hline & & Smoke-free in school buildings & 13 & 0.80 & $0.74-0.86$ & 0.70 & $0.63-0.77$ & 0.64 & $0.56-0.73$ & 4,590 \\
\hline & & Smoke-free throughout school site & 27 & 0.87 & $0.79-0.89$ & 0.76 & $0.70-0.82$ & 0.69 & $0.63-0.77$ & 11,511 \\
\hline \multirow[t]{8}{*}{ Female } & \multirow[t]{4}{*}{ Junior } & Insufficient separation of smoking & 23 & 1.0 & & 1.0 & & 1.0 & & 4,606 \\
\hline & & Separate smoking areas & 23 & 1.15 & $1.02-1.29$ & 1.06 & $1.02-1.29$ & 1.69 & $1.02-2.81$ & 4,558 \\
\hline & & Smoke-free in school buildings & 19 & 1.16 & $1.03-1.31$ & 1.31 & $1.03-1.31$ & 1.33 & $0.76-2.32$ & 3,882 \\
\hline & & Smoke-free throughout school site & 27 & 0.87 & $0.78-0.98$ & 0.75 & $0.78-0.98$ & 0.84 & $0.48-1.48$ & 5,660 \\
\hline & \multirow[t]{4}{*}{ Senior } & Insufficient separation of smoking & 19 & 1.0 & & 1.0 & & 1.0 & & 5,222 \\
\hline & & Separate smoking areas & 28 & 0.81 & $0.75-0.88$ & 0.92 & $0.81-1.04$ & 0.83 & $0.68-1.00$ & 10,139 \\
\hline & & Smoke-free in school buildings & 13 & 1.12 & $1.01-1.23$ & 1.30 & $1.12-1.50$ & 1.05 & $0.84-1.32$ & 3,782 \\
\hline & & Smoke-free throughout school site & 27 & 0.87 & $0.81-0.95$ & 0.93 & $0.82-1.06$ & 0.85 & $0.69-1.03$ & 8,604 \\
\hline
\end{tabular}

OR, Odds ratio; CI, 95\% confidence interval adjusted by school grade and school policy on teachers' smoking in school

of smoke-free buildings was rather higher than that in the schools who had an insufficient separation of smoking-free/ smoking areas.

\section{Discussion}

This study provides the first evidence of a dramatic decrease in smoking prevalence among Japanese adolescents. The
2000 survey showed a decrease in lifetime smoking rate among junior high school boys only and no decrease in prevalence among girls or in regular smoking prevalence among boys. In recent years there has been a trend towards a decreased prevalence of smoking among adolescents in a number of western countries, including the USA [13], England [14], Australia [15], Canada [16], and in adolescent boys in Sweden and Finland [17], but not in a number of other European countries, such as Italy, Russia [18], 
Hungary, and Latvia [17]. The magnitude of decrease found in our 2004 survey was one of the largest reported to date and is the first decrease reported in an Asian country.

In our analysis of the possible factors accounting for the decrease, we identified a decrease in smoking prevalence among family members and an increased proportion of students who had no friends. Parent and sibling smoking is one of the most important predictors of adolescent smoking [6-9, 19, 20]. We observed considerably high odds ratios and population attributable risk of a student's current smoking status with smoking by a family member: the reported decreases in the prevalence of smoking by a father and older brother probably contributed to the decrease among students. However, the prevalence of smoking by mothers of junior high school boys has increased significantly, and this influence on students' smoking behavior should be monitored by periodic surveys. We also observed that having no friend was a protective factor on smoking behavior among senior high school students. Peer smoking is a wellknown predictor of adolescent smoking [20]. The increased proportion of students who reported having no friends indicates a decrease in the human network of students. This may also have contributed to a decrease in peer pressure to start smoking [21].

A governmental measure, called the Act to Prohibit Minors from Smoking, was enacted in 1990 in Japan. According to this law, adults who sell a cigarette to a minor will be punished. However, the number of arrests made under this law has been extremely low, and the law has not had the intended effect. The proportion of current smokers who bought their cigarettes in a store decreased in the 2004 survey, especially for senior high school boys. This may be due to the governmental obligation for sellers to confirm a customers' age (from December 2001, due to a revision of the Act to Prohibit Minors from smoking). However, a significant number of adolescent smokers still buy their cigarettes in stores, and most of the current smokers purchase their cigarettes using cigarette vending machines. The proportion of smokers who buy their cigarettes from vending machine is much higher than that in other countries [22]. Since the number of cigarette vending machines has not decreased [5], banning vending machine and enforcement of age confirmation in stores are important measures to prevent smoking by minors in Japan.

This study also identified the possible efficacy of school regulations on smoking by teachers. Based on the Health Promotion Law issued in 2002, there is a movement by local governments to encourage a smoke-free school site policy with the aim of preventing passive smoking in schools. We observed that a total ban on smoking at a school (entire school site) can be an effective measure in preventing adolescent smoking. Some researchers have emphasized the importance of school smoking restrictions $[23,24]$, whereas review papers have summarized that the effect of school-based smoking control measures is small $[10,11]$. For cultural reasons, the magnitude of the effectiveness of school-based smoking control may be greater in Japan than in Western countries. The inappropriate influence of teachers who smoke outside the school buildings in the view of students may contribute to the relatively higher smoking prevalence in the schools with smoke-free buildings only.

One interesting observation was the contrasting relationship between sexes and school categories (junior or senior) in terms of the increase in smoking by mothers and the effectiveness of school policy. We speculate that smoking by the mother may offset the effect of a school policy on restricting smoking.

In the period 1996 through 2004, cigarette prices in Japan were raised on two occasions, in 1998 and 2003, each time by 20 yen (US $\$ 0.18$ ) per pack ( 20 cigarettes). It is therefore difficult to explain that the decrease in prevalence after 2000 was the result of higher prices. Since adolescent smoking is also influenced by tobacco industry promotions, such as advertising [25-27] and smoking in TV programs or movies [28], we plan to assess the role of cigarette advertizing and smoking scenes in TV programs or movies in Japan.

A limitation of this study is the possibility of misclassification of the smoking status among students. Although this study is an anonymous questionnaire survey, the respondents may have been reluctant to report their actual smoking status due to the more active anti-smoking policies in recent years. However, we considered that the influence of misclassification of reported smoking status was not large because the number of questionnaires with an invalid answer or a contradictory answer did not increase during this study period. Confirmation of the persistence of this decrease in prevalence will require periodic monitoring of adolescent smoking prevalence and related factors.

\section{Conclusion}

In recent years, a number of Western countries have experienced a decrease in the prevalence of smoking among adolescents. The results of the 2004 survey reported here showed a dramatic decrease in smoking prevalence among Japanese adolescents. The current findings demonstrate that possible factors contributing to this decrease is a decreased prevalence of smoking by a father and older brother, restriction in the access of minors to tobacco, an increase in the proportion of students without friends, and a school policy restricting smoking. 
Acknowledgments This study was supported by a grant for a Special Research Project in 1996 and a Public Health Special Research Project in 2000 and 2004 from the Ministry of Health and Welfare Health Science Research Fund in Japan. The sponsors of this study had no role in study design, data collection, data analysis, data interpretation, or writing of the paper. We are grateful to Mr. Michita Nagatsuka, Ms. Sanae Numaguchi, Ms. Kyoko Kawamoto for assembling, inputting, and management of the data, and to Dr. Guy Harris for English editing of the manuscript.

\section{References}

1. Warren CW, Jones NR, Asma S. The Global Tobacco Surveillance System (GYTS) collaborative group. Patterns of global tobacco use in young people and implications for future chronic disease burden in adults. Lancet. 2006;367:749-53.

2. National Committee on Smoking and Health. Report on Smoking and Health (in Japanese). Tokyo, Hokendojin-sha, 2002.

3. Osaki Y, Minowa M, Suzuki K et al. Adolescent smoking behavior in Japan, 1996. Jpn J Alcohol Drug Dependence. 2003;38:483-91.

4. Osaki Y, Suzuki K, Wada K et al. Nationwide survey on adolescent smoking behavior in Japan, year 2000 (in Japanese). Kosei no Shihyo. 2004;51:24-32.

5. Osaki $\mathrm{Y}$, Tanihata $\mathrm{T}$, Ohida $\mathrm{T}$ et al. Adolescent smoking behaviour and cigarette brand preference in Japan. Tobacco Control. 2006;15:172-80.

6. von Bothmer MIK, Mattsson B, Fridlund B. Influences on adolescent smoking behavior: siblings' smoking and norms in the social environment do matter. Health Soc Care Commun. 2002;10:213-20.

7. Bricker JB, Peterson AV, Leroux BG et al. Prospective prediction of children's smoking transitions: role of parents' and older siblings' smoking. Addiction. 2005;100:128-36.

8. Osaki Y, Minowa M, Mei J. A comparison of correlates of cigarette smoking behavior between Jiangxi province, China and Japanese high school students. J Epidemiol. 1999;9:254-60.

9. Soteriades ES, DiFranza JR. Parent's socioeconomic status, adolescents' disposable income, and adolescents' smoking status in Massachusetts. Am J Public Health. 2003;93:1155-60.

10. Sowden A, Arblaster L, Stead L. Community interventions for preventing smoking in young people. The Cochrane Database Systemic Rev 2003, Issue 1. Art. No.:CD001291. doi: 10.1002/14651858.CD001291.

11. Thomas R. School-based programmes for preventing smoking. The Cochrane Database Systemic Rev 2002, Issue 2. Art. No.:CD001293. doi: 10.1002/14651858.CD001293.

12. Cochran WG (ed). Single-stage cluster sampling: clusters of unequal sizes. In: Sampling techniques (3rd edn). New York: Wiley; 1977. p. 249-73.
13. Office on Smoking, Health, and Division of Adolescent and School Health. Cigarette use among high school students-United States, 1991-2003. MMWR. 2004;53:499-502.

14. National Centre for Social Research. Drug use, smoking and drinking among young people in England in 2005. NHS Health and Social Care Information Centre, Public Health Statistics. London, England, National Health Services, 2006.

15. White V, Hayman J. Smoking behaviours of Australian secondary students in 2002. National Drug Strategy Monograph Series No. 54. Canberra, Australia, Department of Australian Government, 2003.

16. Health Canada. The national strategy: moving forward? The 2005 progress report on tobacco control. Ottawa, Canada, The Tobacco Control Liaison Committee, 2005.

17. Hublet A, De Bacquer D, Valimaa $R$ et al. Smoking trends among adolescents from 1990 to 2002 in ten European countries and Canada. BMC Public Health. 2006;6:280.

18. Hibell B, Andersson B, Bjarnason T, et al. The ESPAD (European School Survey Project on Alcohol and Other Drugs) Report. Stockholm, Sweden, The Swedish Council for Information of Alcohol and Other Drugs, 2004.

19. Farkas AJ, Gilpin EA, White MM et al. Association between household and workplace smoking restrictions and adolescent smoking. JAMA. 2000;284:717-22.

20. Alexander C, Piazza M, Mekos D et al. Peers, schools, and adolescent cigarette smoking. J Adolesc Health. 2001;29:22-30.

21. Powell LM, Tauras JA, Ross H. The importance of peer effects, cigarette prices and tobacco control policies for youth smoking behavior. J Health Econ. 2005;24:950-8.

22. Centers for Disease Control and Prevention. Youth tobacco surveillance United States, 2000. CDC surveillance summaries, November 2, 2001. MMWR. 2001;50(SS04):1-84.

23. Moore L, Roberts C, Tudor-Smith C. School smoking policies and smoking prevalence among adolescents: multilevel analysis of cross-sectional data from Wales. Tobacco Control. 2001;10:117-23.

24. Wold B, Currie C, Roberts C et al. National legislation on school smoking restrictions in eight European countries. Health Promot Int. 2004;19:482-8.

25. Pierce JP, Choi WS, Gilpin EA et al. Tobacco industry promotion of cigarettes and adolescent smoking. JAMA. 1998;279:511-5.

26. Pucci LG, Siegel M. Exposure to brand-specific cigarette advertising in magazines and its impact on youth smoking. Prev Med. 1999;29:313-20.

27. MacFadyen L, Hastings G, MacKintosh AM. Cross sectional study of young people's awareness of and involvement with tobacco marketing. Br Med J. 2001;322:513-7.

28. Charlesworth A, Glantz SA. Smoking in the movies increases adolescent smoking: a review. Pediatrics. 2005;116:1516-28. 